\title{
Application of Mobile Micro-learning in College English Teaching
}

\author{
Jiaying Meng \\ Teaching and Research Institute of Foreign Languages, Bohai University, Jinzhou121013, China \\ mengjiaying1@163.com
}

Keywords: mobile devices, micro-learning, college English teaching

\begin{abstract}
Mobile micro-learning is the combination of mobile learning and micro-learning. With regard to the form, it requires students to learn with mobile devices; from the content perspective, it demands small but closely related learning units. Mobile micro-learning has the characteristics of convenience, flexibility and interactivity. Based on the method of comparative studies, this thesis introduces the basic theories about mobile micro-learning, and expounds the concrete application of mobile micro-learning in college English teaching from the perspectives of understanding the connotation and features, designing the e-textbook, updating the teaching mode and establishing a comprehensive assessing system. The data of students' assessing results prove that adopting mobile micro-learning in college English teaching can greatly improve students' learning efficiency.
\end{abstract}

\section{Introduction}

The twenty-first century is an era of information and technology. As network technology and mobile communication technology advance, new ways of learning such as mobile learning and ubiquitous learning come into being in the digital learning field. Although traditional teaching modes still play a very important role, more and more learners adopt mobile micro-learning with smart mobile phone, tablet computer and other mobile devices. The teaching of college English also faces great challenges and opportunities. By taking advantage of these advanced technologies and mobile devices, teachers can utilize multimedia and modern technologies to facilitate traditional teaching of college English. However, how to apply mobile devices to college English teaching is not an easy question. There are many researching projects overseas while in our country, the research on the subject is just in the initial phase.

This thesis aims to do some researches on the subject and proposes a new teaching mode called mobile micro-learning. Combining mobile learning and micro-learning, this teaching mode brings the advantages of network technology and mobile communication technology into full play and can greatly improve learning efficiency. The thesis firstly introduces basic theories about mobile learning and micro-learning; secondly it puts forward concrete ways to apply mobile micro-learning in college English teaching and finally sums up the benefit of conducting mobile micro-learning in college English teaching.

\section{Basic Theories about Mobile Learning and Micro-learning}

\subsection{Definition of Mobile Learning}

The concept of mobile learning was first introduced into China by the international distance educator Desmond Keegan in 2000. After more than ten years of development, mobile learning has become a hot research topic in the field of digital teaching. At present, there is no uniform definition of mobile learning in the academic community. Generally speaking, we can understand it from four different perspectives. Firstly, it can be considered as a form of distance learning; secondly, it can be considered as extension of e-learning because it has the same learning content with e-learning; thirdly, from cognitive perspective, with the nature of mobility and situation- dependence, it can be viewed as a totally new form of learning; fourthly, from the perspective of technology, mobile learning can be regarded as the application of mobile computing in the educational field.[1]Though with different researching perspectives, mobile learning can be generalized as a learning form through which 
learners can receive learning resources with wireless communication network and mobile devices. The features of high flexibility, abundant interactivity and situated learning dramatically meet learners' needs for flexible and personalized learning.

\subsection{Definition of Micro-learning}

In 2004, Austria study expert Lindner first proposed the theory of micro-learning. After ten years of research, the development of this theory has made great progress. Researchers both home and abroad explained the concept of micro-learning from different perspectives. From the perspective of media characteristics, Lindner pointed that micro-learning is a new form of learning based on microcontent and micro-media; [2]Theo Hug defined micro-learning as learning activities based on small learning unit in relatively short learning time; [3] Brock regarded micro-learning as a way of learning which focuses on small, loose yet closely related learning units in digital environment; [4]Professor Zhu Zhiting stressed the new learning experience micro-learning has given to learners. With this learning form, learners' learning activities are not confined by time and place; they can study anytime, anywhere with relatively small learning units for a short time. As a new form of learning, microlearning has the characteristics of convenience and flexibility and are welcomed by more learners.

\subsection{Relationship between Mobile Micro-learning and English Learning}

Although mobile learning and micro-learning both rely on mobile communication technology, wireless network technology and mobile devices to support the learning process, they have different focus. Mobile learning stresses the flexibility of time and space in the learning process, while microlearning emphasizes the shortness of time and the fragmentation of learning content. Mobile microlearning makes full use of the advantages of both mobile learning and micro-learning, that is, to receive micro-content with mobile terminals to study anytime anywhere. Therefore, it is quite convenient to update and supplement learners' existing knowledge system with modular knowledge fragments.

English learning has its distinctive features. Firstly, English learning consists of many different aspects. Horizontally, it covers listening, speaking, reading, writing and translating; vertically, it includes vocabulary, sentence, and discourse and so on; secondly, language learning has the characteristic of relevance with each part closely related; thirdly, language learning stresses the construction of language situations. The input and output of language is very critical to learners; fourthly, the learning of knowledge points can be separated and learners can learn according to the degree of difficulties or their own needs.

To adopt the method of mobile micro-learning to learning English, learners can divide it into different and related micro-content and learn with mobile devices. In this way not only can learners make good use of their fragmented time to learn English but they also can communicate effectively with both their peers and teachers. In the meanwhile, learners can contact correct input through some mobile learning platforms which can satisfy learners' need for language learning environment.

\section{Application of Mobile Micro-learning in College English Teaching}

\subsection{The Connotation and Characteristics of Mobile Micro-learning}

To adopt mobile micro-learning in college English teaching, it is necessary to understand its connotation and characteristics. Although there are many understandings about the definition of mobile micro-learning, basically there exist four typical understandings. Firstly, it can be regarded as a new way of learning existing in the new media environment based on micro-content and micromedia; secondly, it can be considered as learning modules with the learning content divided into small parts; thirdly, it is viewed as a learning form with small but closely related units in digital new media environment; fourthly, its features not only include micro learning units but also learners' involvement and there learning mood.

Combining these four understandings of mobile micro-learning, its definition should include four elements namely the learner, the micro-content, the micro-media and the micro-environment.

Micro learner is the main body of micro learning. In the micro learning environment, the subject of learning is no longer confined to the traditional sense of education as to the students in the school, it can also include office workers, freelancers, older people, etc.;micro learning provides the 
possibility of universal learning;micro content is the object of micro learning. In the society of lifelong learning, micro learning can meet the needs of different learners for different knowledge and skills. According to this understanding, the content of micro learning is no longer confined to the traditional teaching materials, but in all aspects of life;micro media is the carrier of micro learning, various communication devices can be used for micro learning. For the hardware, you can use a variety of mobile terminals, mobile phones, tablet PCs, etc.; for the software, you can use SMS, micro-blog, WeChat, cloud storage, etc.; the micro environment is the support for micro learning, not only referring to the interaction between cable and wireless communication network which is used for data transmission but also including interaction between the micro learners and between learners and micro content, as well as the interaction between learners and teachers.

\subsection{Designing E-textbook for Mobile Micro-learning}

The content of micro-learning has to be with reasonable amount of information and with prominent key points. Due to the limitations of mobile devices, the selection and presentation of learning content is different from the traditional teaching content. The selection of the content should be concise, focused, and should not choose long paragraphs as the learning content. In the meanwhile, the design of the e-book has to conform to students' learning pattern and it shouldn't be considered as an electronic presentation of traditional textbook. It should include multimedia resources and multiple interactive modes. The design can be seen in Fig.1, with many key elements such as teaching objects, module design, interface design, interactions and processing of multimedia material, etc.

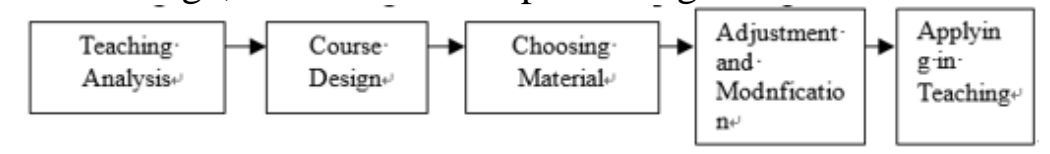

Fig.1 Process of producing E-textbook

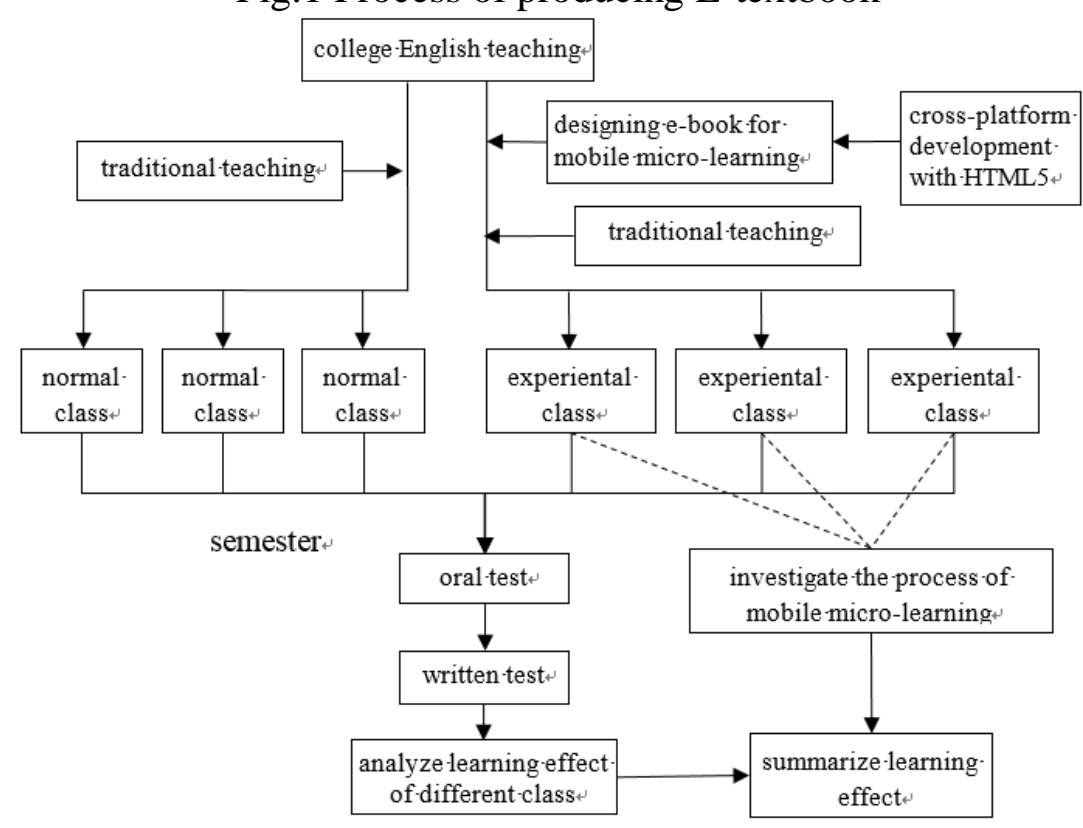

\subsection{Updating Teaching Mode}

Fig. 2 teaching mode for mobile micro-learning

The goal of applying mobile micro-learning to college English teaching is to cultivate students' comprehensive ability of using English, especially reading, listening and speaking ability, so that students can communicate effectively in English in their work and social interactions and in the meanwhile to enhance students' ability of autonomous learning and improve their comprehensive cultural quality. The teaching modes have to be changed to conform to new mobile e-textbook and new leaning activities. The implementing of new teaching mode is shown in Feagure2.

According to the teaching design, students participating in mobile micro-learning are provided with e-textbook and have to conduct autonomous learning under teacher's guidance; and they have to be examined with students not involving in mobile micro-learning. Data from their results will be used to check the effect of mobile micro-learning. 


\subsection{Establishing a Comprehensive Assessment System}

It is necessary to build a formative assessment system when conducting mobile micro-learning, for it ensures a smooth and effective learning process and helps to keep learners' enthusiasm in learning.

Traditional summative assessment emphasizes book knowledge and scores in examinations ignoring its actual use in life and frustrating students' learning interest and initiatives. Whereas, the formative assessment based on constructivism stresses self-exploration of the knowledge and encourages a self-evaluation of the learners through which they can adjust learning strategies.

When applying mobile micro-learning, teachers can establish a sound and comprehensive assessment system including self-assessment, peer- assessment and teacher-assessment. [5]Selfassessment causes a positive reflection upon learners' learning content, learning process and learning attitude; peer-assessment ensures more effective collaborative learning and teacher-assessment can help to find out problems in online learning and encourages students to learn more actively.

\section{Summary}

Combining mobile learning and micro-learning, the form of mobile micro-learning has the characteristics of convenience, flexibility and interactivity. By applying this method in college English teaching, teachers can divide knowledge into small but closely related learning units and assign them to students. Students can learn with mobile devices in their fragmented time. For one thing, students can have clear learning objects and work for it; for another, they can make better use of their fragmented time. Mobile micro-learning can not only enhance students' interest and enthusiasm in learning English, but also improve their ability to conduct autonomous learning and the interaction between teachers and students. The data of students' assessing results prove that it can greatly improve students' learning efficiency.

\section{References}

[1]. Zhang Hongling, Zhuye, Sun Guifang, et al. Web-Based Foreign Language Teaching: Theories and Designing [M]. Shanghai: Shanghai Foreign Language Education Press, 2000, p.67-80.(In Chinese)

[2]. Lindner M, Peter A. Bruck. Micromedia and Corporate Learning: Proceedings of the 3rd International Microlearning 2007 Conference [M]. Innsbruck: Innsbruck University Press, 2007,p.52-55

[3]. Hug T. Microlearning: A New Pedagogical Challenge (Introductory Note) [C]. 2005.

[4]. Bruck P.A, Multiwall L B, Foerster F A. Mobile learning with micro-content: A framework and evaluation [J]. 2012.

[5]. McNamara M J, Deane D. Self-Assessment Activities: Toward Language Autonomy in Language Learning [J]. Tesol Journal, (1994) No.5, p.17-21. 